\title{
Lithocholic acid induces endoplasmic reticulum stress, autophagy and mitochondrial dysfunction in human prostate cancer cells
}

\author{
Ahmed A Gaffr ${ }^{1,2}$, Hossam M Draz ${ }^{1,3}$, Alexander A Goldberg ${ }^{1,4}$, Mohamed A Bashandy ${ }^{2}$, Sayed Bakry ${ }^{2}$,

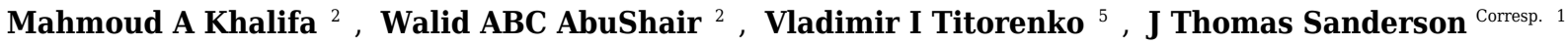 \\ 1 Institut Armand-Frappier, Institut National de la Recherche Scientifique (INRS), Laval, QC, Canada \\ 2 Zoology Department, Faculty of Science, Al-Azhar University, Cairo, Egypt \\ 3 Department of Biochemistry, National Research Centre, Dokki, Cairo, Egypt \\ 4 McGill University Health Centre, Montréal, QC, Canada \\ 5 Department of Biology, Concordia University, Montréal, QC, Canada \\ Corresponding Author: J Thomas Sanderson \\ Email address: thomas.sanderson@iaf.inrs.ca
}

Lithocholic acid (LCA) is a secondary bile acid that is selectively toxic to human neuroblastoma, breast and prostate cancer cells, whilst sparing normal cells. We previously reported that LCA inhibited cell viability and proliferation and induced apoptosis and necrosis of androgen-dependent LNCaP and androgen-independent PC-3 human prostate cancer cells. In the present study, we investigated the roles of endoplasmic reticulum (ER) stress, autophagy and mitochondrial dysfunction in the toxicity of LCA in PC-3 and autophagy deficient, androgen-independent DU-145 cells. LCA induced ER stressrelated proteins, such as CCAAT-enhancer-binding protein homologous protein (CHOP), and the phosphorylation of eukaryotic initiation factor 2-alpha (p-elF2 $\alpha$ ) and c-Jun N-terminal kinases ( $p$-JNK) in both cancer cell-types. The p53 upregulated modulator of apoptosis (PUMA) and B cell lymphoma-like protein 11 (BIM) levels were decreased at overtly toxic LCA concentrations, although PUMA levels increased at lower LCA concentrations in both cell lines. LCA induced autophagy-related conversion of microtubule-associated proteins 1A/1B light chain 3B (LC3BI to LC3BII), and autophagy-related protein ATG5 in PC-3 cells, but not in autophagy-deficient DU-145 cells. LCA (>10 $\mu \mathrm{M})$ increased levels of reactive oxygen species (ROS) concentration-dependently in PC-3 cells, whereas ROS levels were not affected in DU-145 cells. Salubrinal, an inhibitor of elF2 $\alpha$ dephosphorylation and ER stress, reduced LCA-induced CHOP levels slightly in PC-3, but not DU-145 cells. Salubrinal pre-treatment increased the cytotoxicity of LCA in PC-3 and DU-145 cells and resulted in a statistically significant loss of cell viability at normally non-toxic concentrations of LCA. The late-stage autophagy inhibitor bafilomycin Al exacerbated LCA toxicity at subtoxic LCA concentrations in PC-3 cells. The antioxidant $\alpha$-tocotrienol strongly inhibited the toxicity of 
LCA in PC-3 cells, but not in DU-145 cells. Collectively, although LCA induces autophagy and ER stress in PC-3 cells, these processes appear to be initially of protective nature and subsequently consequential to, but not critical for the ROS-mediated mitochondrial dysfunction and cytotoxicity of LCA. The full mechanism of LCA-induced mitochondrial dysfunction and cytotoxicity in the similarly sensitive DU-145 cells remains to be elucidated. 


\section{Lithocholic acid induces endoplasmic reticulum stress, autophagy and}

2 mitochondrial dysfunction in human prostate cancer cells

3 *Ahmed Gafar ${ }^{1,2}$, Hossam Draz ${ }^{1,3}$, Alexander A Goldberg 1,4, Mohammed A. Bashandy ${ }^{2}$,

4 Sayed Bakry ${ }^{2}$, Mahmoud A. Khalifa ${ }^{2}$, Walid AbuShair ${ }^{2}$, Vladimir I. Titorenko ${ }^{5}$ and J. Thomas

5 Sanderson ${ }^{1}$.

6 1. INRS-Institut Armand-Frappier, Laval, QC Canada

7 2. Zoology Department, Faculty of Science, Al-Azhar University, Egypt

8 3. Department of Biochemistry, National Research Centre, Dokki, Cairo, Egypt

9 4. McGill University Health Centre, Montréal, QC, Canada

10 5. Department of Biology, Concordia University, Montreal, QC, Canada

12 Corresponding author:

13 J. Thomas Sanderson

14531 boulevard des Prairies, Laval, QC, H7V 1B7, Canada

15 Email address: thomas.sanderson@iaf.inrs.ca 


\section{Abstract}

Lithocholic acid (LCA) is a secondary bile acid that is selectively toxic to human neuroblastoma, breast and prostate cancer cells, whilst sparing normal cells. We previously reported that LCA inhibited cell viability and proliferation and induced apoptosis and necrosis of androgendependent LNCaP and androgen-independent PC-3 human prostate cancer cells. In the present study, we investigated the roles of endoplasmic reticulum (ER) stress, autophagy and mitochondrial dysfunction in the toxicity of LCA in PC-3 and autophagy deficient, androgenindependent DU-145 cells. LCA induced ER stress-related proteins, such as CCAAT-enhancerbinding protein homologous protein (CHOP), and the phosphorylation of eukaryotic initiation factor 2-alpha (p-eIF2 $\alpha$ ) and c-Jun N-terminal kinases (p-JNK) in both cancer cell-types. The p53 upregulated modulator of apoptosis (PUMA) and B cell lymphoma-like protein 11 (BIM) levels were decreased at overtly toxic LCA concentrations, although PUMA levels increased at lower LCA concentrations in both cell lines. LCA induced autophagy-related conversion of microtubule-associated proteins 1A/1B light chain 3B (LC3BI to LC3BII), and autophagyrelated protein ATG5 in PC-3 cells, but not in autophagy-deficient DU-145 cells. LCA (>10 $\mu \mathrm{M})$ increased levels of reactive oxygen species (ROS) concentration-dependently in PC-3 cells, whereas ROS levels were not affected in DU-145 cells. Salubrinal, an inhibitor of eIF2 $\alpha$ dephosphorylation and ER stress, reduced LCA-induced CHOP levels slightly in PC-3, but not DU-145 cells. Salubrinal pre-treatment increased the cytotoxicity of LCA in PC-3 and DU-145 cells and resulted in a statistically significant loss of cell viability at normally non-toxic concentrations of LCA. The late-stage autophagy inhibitor bafilomycin A1 exacerbated LCA toxicity at subtoxic LCA concentrations in PC-3 cells. The antioxidant $\alpha$-tocotrienol strongly inhibited the toxicity of LCA in PC-3 cells, but not in DU-145 cells. Collectively, although LCA induces autophagy and ER stress in PC-3 cells, these processes appear to be initially of protective nature and subsequently consequential to, but not critical for the ROS-mediated mitochondrial dysfunction and cytotoxicity of LCA. The full mechanism of LCA-induced mitochondrial dysfunction and cytotoxicity in the similarly sensitive DU-145 cells remains to be elucidated. 


\section{INTRODUCTION}

Prostate cancer is the second most common cancer worldwide in males and the fourth most common cancer overall, with more than 1,112,000 new cases diagnosed in 2012, representing $15 \%$ of male cancer cases and $8 \%$ of all cancers (Ferlay et al., 2015). In Western men, prostate cancer diagnosis ranks first among male cancers and second as cause of cancer-related death (Malvezzi et al., 2015; Society, 2015a; Society, 2015b). Standard treatment of prostate cancer consists of surgery (prostatectomy), antihormonal therapy and radiotherapy. Although these treatments are successful for early-stage prostate cancer, they each have potentially serious sideeffects (Martin and D'Amico, 2014; Nguyen et al., 2015), among which some that last a life-time (Sanda et al., 2008). Androgen-deprivation therapy uses drugs that blocking the action of male sex hormones either through androgen receptor antagonism (bicalutamide, hydroxyflutamide) or inhibition of androgen biosynthesis (finasteride, abiraterone). These treatments are initially effective in controlling androgen-dependent prostate tumor growth, although side-effects include increased insulin-resistance, bone density loss, hypogonadism, gynecomastia, muscle mass loss and fatigue (Conde and Aronson, 2003; Nguyen et al., 2015). In addition, a certain percentage of tumors that have undergone androgen-deprivation therapy progresses to an androgenindependent state, which is difficult to treat resulting in increased mortality. The limitations of current standard treatments of prostate cancer has encouraged the search for safer and more effective molecules based on naturally occurring compounds.

Lithocholic acid (LCA) is a secondary bile acid produced by microflora in the gut, which we found to exhibit selective toxicity to human neuroblastoma cells and prostate cancer cells at relatively low concentrations that did not affect normal cells (Goldberg et al., 2011; Goldberg et al., 2013). LCA triggered both intrinsic and extrinsic pathways of apoptotic cell death that were, at least in part, caspase-dependent. In addition, LCA selectively decreased the viability of human breast cancer and rat glioma cells (Goldberg et al., 2011). Various bile acids have been reported to have anti-neoplastic and anti-carcinogenic properties in a number of cancer cell models: chenodeoxycholic acid (CDCA) reduced growth of tamoxifen-resistant breast cancer cells by downregulation of human epidermal growth factor receptor 2 (HER2) promoter activity (Giordano et al., 2011), LCA and several of its synthetic enantiomers reduced colon cancer cell proliferation and viability (Katona et al., 2009). Deoxycholic acid (DCA), ursodeoxycholic acid (UDCA) and their taurine-derivatives delayed cell cycle progression in Jurkat human T leukemia 
cells and DCA induced apoptosis (Fimognari et al., 2009). These findings indicate that the bile acid structure may form the basis for the development of potent and selective drugs for the treatment of various cancers including those of the prostate.

The mechanisms underlying the cytotoxicity of LCA are not well understood and remain a continuing topic of investigation. Studies have found that certain bile acids can induce apoptosis via a variety of mechanisms including chronic endoplasmic reticulum (ER) stress (Perez and Briz, 2009), autophagy (Gao et al., 2014) or disruption of mitochondrial function (Goldberg et al., 2013). The endoplasmic reticulum is cell organelle responsible for the synthesis, folding and maturation of proteins, the storage and release of intracellular calcium $(\mathrm{Ca} 2+)$ and a large number of biotransformation reactions. A variety of factors (radiation, pathogens, hypoxia, disease states and chemical agents) can disrupt healthy ER function, resulting in a so-called unfolded protein response (UPR), due to the accumulation of unfolded or misfolded proteins in the lumen of the ER. As an adaptive response to these stress factors, the UPR aims to restore normal cell function by halting protein translation, degrading misfolded proteins and increasing the production of molecular chaperones involved in protein folding. However, chronic activation of the UPR fails to promote cell survival and the cell is broken down by a proapoptotic ER stress-mediated response pathway. CCAAT-enhancer-binding protein homologous protein $(\mathrm{CHOP})$ is a transcriptional regulator induced by ER stress, which is a modulator of ER stressmediated apoptosis (Marciniak et al., 2004) and autophagy (Shimodaira et al., 2014). CHOP levels may be increased through activation of various ER stress sensor-pathways, including those initiated by activating transcription factor 6 (ATF6), inositol-requiring enzyme 1 alpha (IRE1 $\alpha$ ) and protein kinase R-like endoplasmic reticulum kinase (PERK), the latter which phosphorylates eukaryotic initiation factor 2-alpha (eIF2 $\alpha$ ), and the downstream transcription factor ATF4 which in turn induces the transcription of CHOP.

Autophagy is a catabolic process for the autophagosomic/lysosomal degradation of bulk cytoplasmic contents (Reggiori and Klionsky, 2002; Codogno and Meijer, 2005). Autophagy is generally activated by nutrient deprivation but is also important in physiological processes such as fetal development and cell differentiation, as well as diseases such as neurodegeneration, infection and cancer (Levine and Yuan, 2005). The molecular machinery of autophagy was largely uncovered in yeast by the discovery of autophagy-related genes (Atg). Formation of the autophagosome involves a ubiquitin-like conjugation system in which Atg12 is covalently bound 
110 to Atg5 and targeted to autophagosomal vesicles (Mizushima et al., 1998a; Mizushima et al.,

111 1998b). Upon induction of autophagy, a fraction of microtubule-associated proteins 1A/1B light

112 chain 3 (LC3-I) is conjugated to phosphotidylethanolamine (PE) to produce LC3-II proteins,

113 which are required for autophagosome membrane expansion and fusion. (Tanida I, Ueno T,

114 Kominami E (2004). LC3-I-to-II conversion is reliable marker of autophagosome formation.

115 (Mizushima N. et al (2001)

116 Bile acids have also been reported to induce apoptosis via disruption of mitochondrial function,

117 ligand-independent activation of death receptor pathways and modulation of certain members of

118 the Bcl2 protein family. We have previously shown that LCA induces intrinsic and extrinsic 119 apoptosis in LNCaP and PC-3 prostate cancer cells that involved a decrease in the mitochondrial 120 protein $\mathrm{Bcl}-2$ and cleavage of Bax, concomitant with an increase of mitochondrial outer 121 membrane permeability. It has been suggested that the well-known solubilising properties of bile 122 acids could explain disruption of (mitochondrial) membranes and induction of mitochondrial 123 dysfunction leading to cell death. However, the lack of or far poorer toxicity of several 124 enantiomers of toxic bile acids suggests physico-chemical properties alone cannot explain cell 125 toxicity (Katona et al., 2009) and that a specific three-dimensional structure is required to 126 explain the selectivity of LCA-mediated toxicity in cancer cells.

127 Our present study aims to investigate to which extent the involvement of ER stress, autophagy or 128 disruption of mitochondrial function is critical to LCA-induced prostate cancer cell death.

\section{MATERIALS AND METHODS}

\section{Cell lines and reagents}

132

PC3 and DU-145 cells were obtained from the American Type Culture Collection (Manassas, VA). PC-3 cells were grown in 1:1 (v/v) Dulbecco's modified Eagle medium/Ham's F-12 nutrient mix (DMEM/F12, Life Technologies, Grand Island, NY) supplemented with 10\% fetal bovine serum (FBS; Mediatech, Corning, Manassas, VA) and 1\% penicillin/streptomycin (Life Technologies). DU-145 and RWPE-1 cells were cultured in RPMI-1640 medium (Life Technologies) supplemented with 10\% FBS, 1\% HEPES , 1\% sodium pyruvate (Sigma-Aldrich, St. Louis, MO) and penicillin/streptomycin. All cells were incubated in a humidified atmosphere 
139 of $95 \%$ air and $5 \% \mathrm{CO}_{2}$ at $37^{\circ} \mathrm{C}$. LCA was purchased from Sigma-Aldrich and dissolved in

140 DMSO as $100 \mathrm{mM}$ a stock solution and 1000-fold concentrated serial dilutions were prepared in

141 DMSO for treatment of the cells. Bafilomycin A1, salubrinal and D- $\alpha$-tocotrienol (Sigma-

142 Aldrich) were dissolved in DMSO at 1000-fold stock solutions of $2 \mu \mathrm{M}, 20 \mathrm{mM}$ and $20 \mathrm{mM}$,

143 respectively

144 Cell viability

145 Each cell type was added to 96-well plates at a density of $1 \times 10^{4}$ cells/well in $200 \mu 1$ of 146 complete medium. After $24 \mathrm{~h}$, medium was replaced with fresh medium containing $2 \%$ dextran-

147 coated charcoal-treated (stripped) FBS and various concentrations of LCA $(0,5,10,25,50$ and

$14875 \mu \mathrm{M}$ ) in a final DMSO concentration in culture medium of $0.1 \%$. Cell viability was assessed

149 using a WST-1 Cell Proliferation Reagent kit (Roche, Laval, QC) according to the

150 manufacturer's instructions. Absorbance was measured at $440 \mathrm{~nm}$ using a SpectraMax M5

151 multifunctional spectrophotometer (Molecular Devices, Sunnydale, CA).

\section{Fluorescence microscopy}

153 PC-3 and DU-145 cells were added to 24 -well plates at a density of $1 \times 10^{5}$ cells/well in $1 \mathrm{ml}$ of 154 complete medium. After $24 \mathrm{~h}$, cells were treated with several concentrations of LCA $(0,1,3,10$ 155 and $30 \mu \mathrm{M})$ in fresh medium containing 2\% stripped FBS and another $24 \mathrm{~h}$ later, Hoechst 33342 156 (Sigma-Aldrich) and propidium iodide (Invitrogen, Carlsbad, CA) were each added at a 157 concentration of $1 \mu \mathrm{g} / \mathrm{ml}$ per well. After a $15 \mathrm{~min}$ incubation at $37^{\circ} \mathrm{C}$, cells were observed and 158 counted under a Nikon Eclipse (TE-2000U) inverted fluorescent microscope at $20 \mathrm{X}$ 159 magnification. Hoechst- and propidium iodide-positive cells were made visible using filter cubes 160 with excitation wavelengths of 330-380 nm and 532-587 nm, respectively. To measure 161 autophagy, PC-3 cells were exposed to $\operatorname{LCA}(0,3,10,30$ and $50 \mu \mathrm{M})$ for $24 \mathrm{~h}$ and then stained 162 with Hoechst 33342 and $2 \mu \mathrm{L}$ of Cyto-ID® Green Detection Reagent (ENZ-51031-K200, Enzo 163 Life Science, Farmingdale, NY). After a 15 min incubation at $37^{\circ} \mathrm{C}$, cells were observed and 164 counted under a Nikon Eclipse (TE-2000U) inverted fluorescent microscope at $20 \mathrm{X}$ 165 magnification.

\section{SDS-PAGE and immunoblot analysis}


167 Cells were added to 6-well Cell-Bind plates (Fisher Scientific, Ottawa, ON) at a density of $7.5 \mathrm{x}$

$16810^{5}$ cells/well in $2 \mathrm{ml}$ of complete culture medium and allowed to adhere for $24 \mathrm{~h}$. Cells were 169 then exposed to $\operatorname{LCA}(0,3,10,30$ and $50 \mu \mathrm{M})$ in fresh medium with $2 \%$ stripped FBS for 1,8 or $17024 \mathrm{~h}$, dependent on the experiment. Adherent cells were collected using a cell scraper, then 171 rinsed three times in cold phosphate-buffered saline (PBS) followed by centrifugation at $700 \times \mathrm{g}$ 172 for $5 \mathrm{~min}$. After removing the PBS, the cell pellets were lysed in RIPA buffer containing $1 \times$ 173 protease and phosphatase inhibitor cocktail. Then, cell lysates were centrifuged at 15,000 rpm for $17415 \mathrm{~min}$ at $4^{\circ} \mathrm{C}$ and protein concentrations in the supernatant were determined using a BCA 175 protein assay kit (Pierce Biotechnologies, Rockford, IL). Proteins (40 $\mu \mathrm{g})$ were diluted with 176 loading buffer and boiled for $5 \mathrm{~min}$, then loaded onto $10 \%$ sodium dodecyl sulfate177 polyacrylamide gels. After electrophoresis, gels were transferred to polyvinylidene diflouride 178 (PVDF) membranes using a Trans-Blot Turbo System (Bio-Rad, Mississauga, ON). Membranes

179 180 181 182 183 184

185

186

188 189 190

191 192 193 194 195 were then blocked using Tris-buffered saline (TBS) containing 5\% milk powder (blocking buffer) for $1 \mathrm{~h}$ at room temperature, after which the membranes were incubated overnight in blocking buffer with the appropriate primary antibodies (anti CHOP, eIF2 $\alpha$, p- eIF2 $\alpha, \mathrm{JNK}$, pJNK, PUMA, BIM, cleaved caspase 3, LC3BI/II, ATG5 and $\beta$-actin at 1:1000 dilution; Cell Signaling, Beverly, MA) at $4^{\circ} \mathrm{C}$. The next day, membranes were washed three times with Trisbuffered saline containing $0.1 \%$ Tween (TBS-T) followed by a 1-h incubation with the appropriate secondary antibody at room temperature. Membranes were washed another three times with TBS-T and then incubated with Immobilon Western Chemiluminescent Horseradish Peroxidase Substrate (EMD Millipore, Billerica, MD ) for 5 min to make the bands visible; membranes were sealed in plastic wrap and photographed using a ChemiDoc gel documentation system (Bio-Rad). $B$-actin was used as reference protein and loading control.

\section{Gene-silencing using small interfering RNA (siRNA)}

CHOP expression was silenced by transfecting PC-3 and DU-145 cells with SMARTpool ONTARGETplus siRNA oligonucleotides selective for CHOP (Dharmacon, Lafayette, CO) using lipofectamine RNAiMAX (Life Technologies, Burlington, ON) in serum free Opti-MEM according to manufacturer's protocols. ON-TARGETplus Non-targeting Control siRNA was used as negative control. After a 24-h transfection period, cells were exposed to various 
196 concentrations of $\operatorname{LCA}(0,10$ and $30 \mu \mathrm{M})$ for $24 \mathrm{~h}$. CHOP protein levels were evaluated by

197 immunoblotting as described above.

198 Measurement of reactive oxygen species (ROS)

199 PC3 and DU-145 cells were added to 96-well plates at a concentration of $1 \times 10^{4}$ cells/well in $200200 \mu \mathrm{l}$ of their respective culture medium containing $2 \%$ stripped FBS. After $24 \mathrm{~h}$, medium was 201 removed and the cells were incubated in prewarmed PBS at $37^{\circ} \mathrm{C}$ containing $10 \mathrm{mM}$ fluorescent 202 ROS probe (CM-H2DCFDA; Life Technologies). After 30 minutes, the PBS mixture was 203 removed and cells were exposed to various concentrations of LCA or $1 \mu \mathrm{M} \mathrm{H}_{2} \mathrm{O}_{2}$ for 60 minutes 204 at $37^{\circ} \mathrm{C}$ temperature. In experiments with $\alpha$-tocotrienol and $\mathrm{N}$-acetylcysteine. cells were 205 preincubated with the antioxidants for $4 \mathrm{~h}$ prior to exposure to LCA. ROS production was 206 quantified using a SpectraMax M5 multifunctional spectrophotometer (Molecular Devices, 207 Sunnydale, CA) with an excitation wavelength of 490 and emission wavelength of $545 \mathrm{~nm}$. 


\section{Statistical analysis}

210 Statistical analyses were performed using GraphPad Prism version 5.0 (GraphPad Software, San

211 Diego, CA). Results are presented as means \pm standard deviations of at least three experiments.

$212 \mathrm{IC}_{50}$ values were determined from concentration-response curves by non-linear curve-fitting.

213 Statistically significant differences of LCA treatments compared to vehicle control were

214 determined by one-way analysis of variance (ANOVA) and a Dunnett post-hoc test or by two-

215 way ANOVA and a Bonferroni post-hoc test when assessing differences between concentration-

216 response curves. A p-value less than 0.05 was considered statistically significant.

217 
218

219

220

221

222

223

224

225

226

227

228

229

230

231

232

233

\section{RESULTS}

\section{LCA decreases the viability and induces apoptosis and necrosis of PC-3 and DU-145} human prostate cancer cells

A 24-h exposure to LCA reduced the viability of PC-3 and DU-145 cells concentrationdependently, with $\mathrm{IC}_{50}$ values of $32.0 \mu \mathrm{M}$ and $30.4 \mu \mathrm{M}$, respectively (Fig 1). The viability of RWPE-1 immortalized normal prostate epithelial cells was not affected by concentrations of LCA between 5 and $75 \mu \mathrm{M}$ (Fig 1). Hoechst 33342 and propidium iodide-staining of PC-3 and DU-145 cells exposed for $24 \mathrm{~h}$ to LCA showed a significant concentration-dependent increase in staining, with both necrotic (and late-apoptotic) and early-apoptotic cells starting to appear at a concentration at or above $3 \mu \mathrm{M}$ (Fig 2).

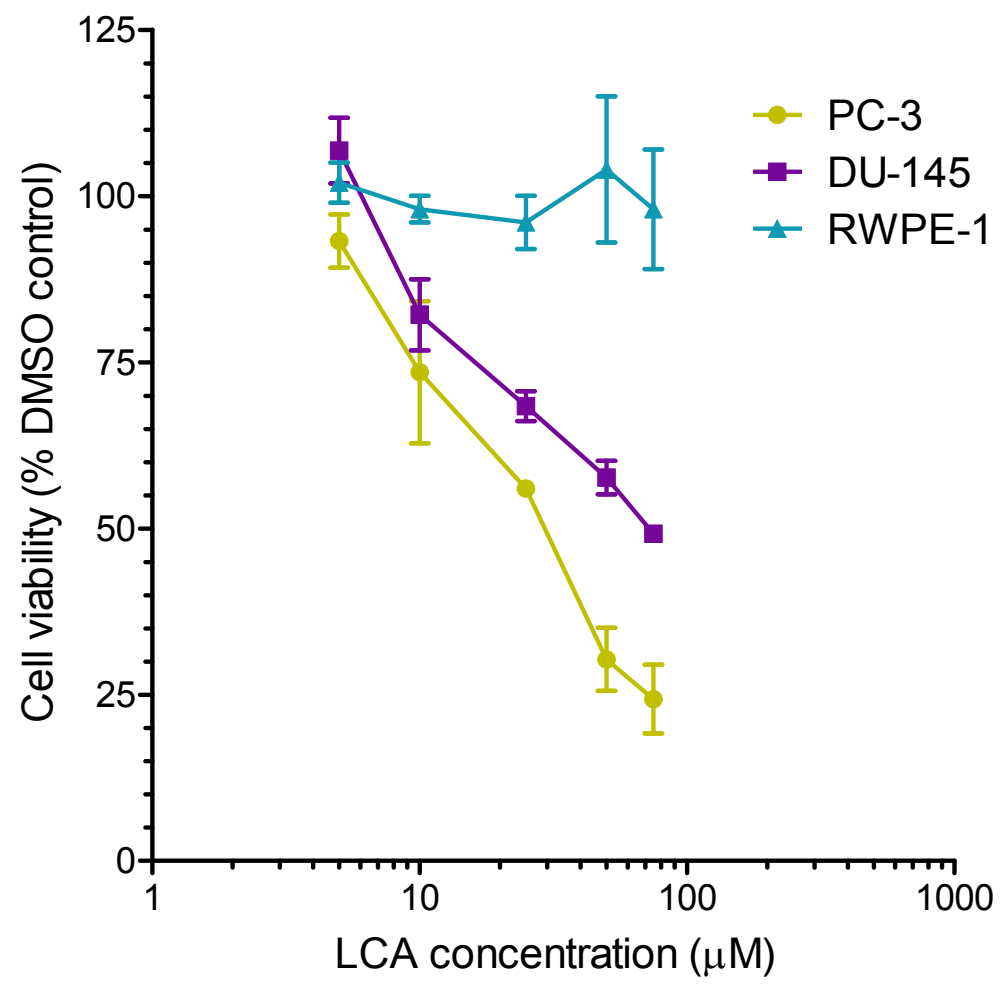

Figure 1. Lithocholic acid (LCA) decreases the viability of PC-3 and DU-145 human prostate cancer cells, but not RWPE-1 immortalized normal prostate epithelial cells. Cells were exposed to increasing concentrations of LCA (5-75 $\mu \mathrm{M})$ for $24 \mathrm{~h} . I C_{50}$ values for LCA-induced cytotoxicity in PC-3 and DU-145 cells were $32.0 \mu \mathrm{M}$ and $30.4 \mu \mathrm{M}$, respectively. Experiments were performed three times; per experiment, each concentration was tested in triplicate. 
Figure 2. Lithocholic acid (LCA) induces apoptotic and necrotic death of PC-3 and DU-145 prostate cancer cells. Apoptotic 


\section{LCA induces ER stress in PC-3 and DU-145 cells}

240 To determine whether the ER stress pathway was involved in LCA-induced prostate cancer cell 241 death, we determined the concentration- and time-dependent effects of LCA on p-JNK, JNK, p242 eIF2 $\alpha$, eIF2 $\alpha$ and CHOP protein levels, as well as on levels of BIM and PUMA in PC-3 and DU243145 cells exposed for $24 \mathrm{~h}$ to sub-cytotoxic ( 3 and $10 \mu \mathrm{M})$ and overtly cytotoxic (30 and $50 \mu \mathrm{M})$ 244 concentrations of LCA. Levels of BIM and PUMA were decreased concentration-dependently by 245 LCA in PC-3 and DU-145 cells, although in DU-145 cells PUMA levels increased at 3 and 10 $246 \mu \mathrm{M}$ before decreasing strongly at overtly cytotoxic concentrations (Fig 3). LCA concentration247 dependently increased levels of p-JNK (46 and $54 \mathrm{KDa})$ and CHOP (27 kDa) in PC-3 and DU248145 cells (Fig 3). Phosphorylation of eIF2 $\alpha$ was increased in a concentration-dependent manner in DU-145 cells, but was poorly detectable in PC-3 cells after a $24 \mathrm{~h}$ exposure to any of the LCA 250 concentrations (Fig 3).

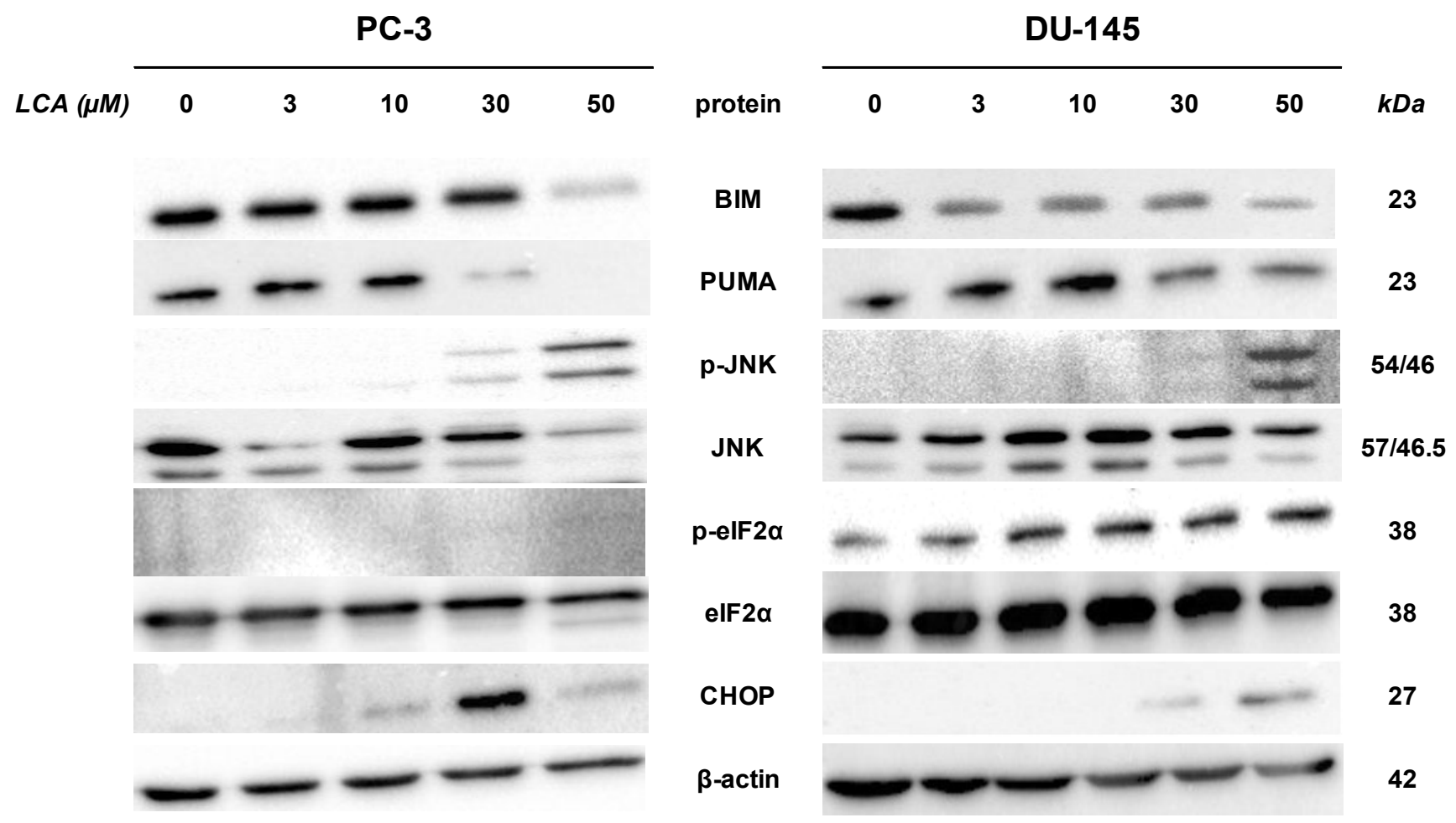

Figure 3. Lithocholic acid (LCA) induces ER stress in PC-3 and DU-145 prostate cancer cells. Cells were exposed to 3, 10, 30 or $50 \mu M$ of LCA for 24 h. BIM, PUMA, p-JNK, JNK, eIF2 $\alpha$, peIF2 $\alpha, C H O P$ and $\beta$-actin were detected by immunoblotting; one representative gel of three is 255 shown. 
257 To determine the effects of LCA on the ER stress response at earlier time-points, PC-3 and DU-

258145 cells were exposed to cytotoxic concentrations (30 and $50 \mu \mathrm{M})$ of LCA for 1 and $8 \mathrm{~h}$ (Fig 4).

259 BIM and PUMA levels were decreased concentration-dependently by LCA in both cell lines. In

260 PC-3 cells BIM levels were somewhat higher at $8 \mathrm{~h}$ than $1 \mathrm{~h}$ (Fig 4), which appeared to be an

261 effect of the vehicle control, although they were, nevertheless, decreased by LCA, as was

262 observed after $24 \mathrm{~h}$ exposure (Fig 3). In DU-145 cells BIM levels were detectable at $1 \mathrm{~h}$ but not

263 at $8 \mathrm{~h}$. PUMA levels were decreased concentration-dependently by LCA in both cell lines,

264 although basal levels in each cell line increased between 1 and $8 \mathrm{~h}$ of culture (Fig. 4). Levels of

265 p-JNK underwent a biphasic response in both cell lines with expression levels appearing lower

266 after $8 \mathrm{~h}$ than $1 \mathrm{~h}$ of exposure to LCA, whereas levels were increased again after $24 \mathrm{~h}$ of

267 exposure, in particular to $50 \mu \mathrm{M}$ LCA. Levels of p-eIF2 $\alpha$ increased concentration-dependently

268 after a $1 \mathrm{~h}$ and $8 \mathrm{~h}$ exposure of PC-3 and DU-145 cells to LCA (Fig. 4), but decreased time-

269 dependently in both cell lines and, after $24 \mathrm{~h}$ of exposure, to non-detectable levels in PC-3 cells

270 (Fig. 3). LCA (30 and $50 \mu \mathrm{M}$ ) visibly increased CHOP levels after $8 \mathrm{~h}$ in both cell lines.

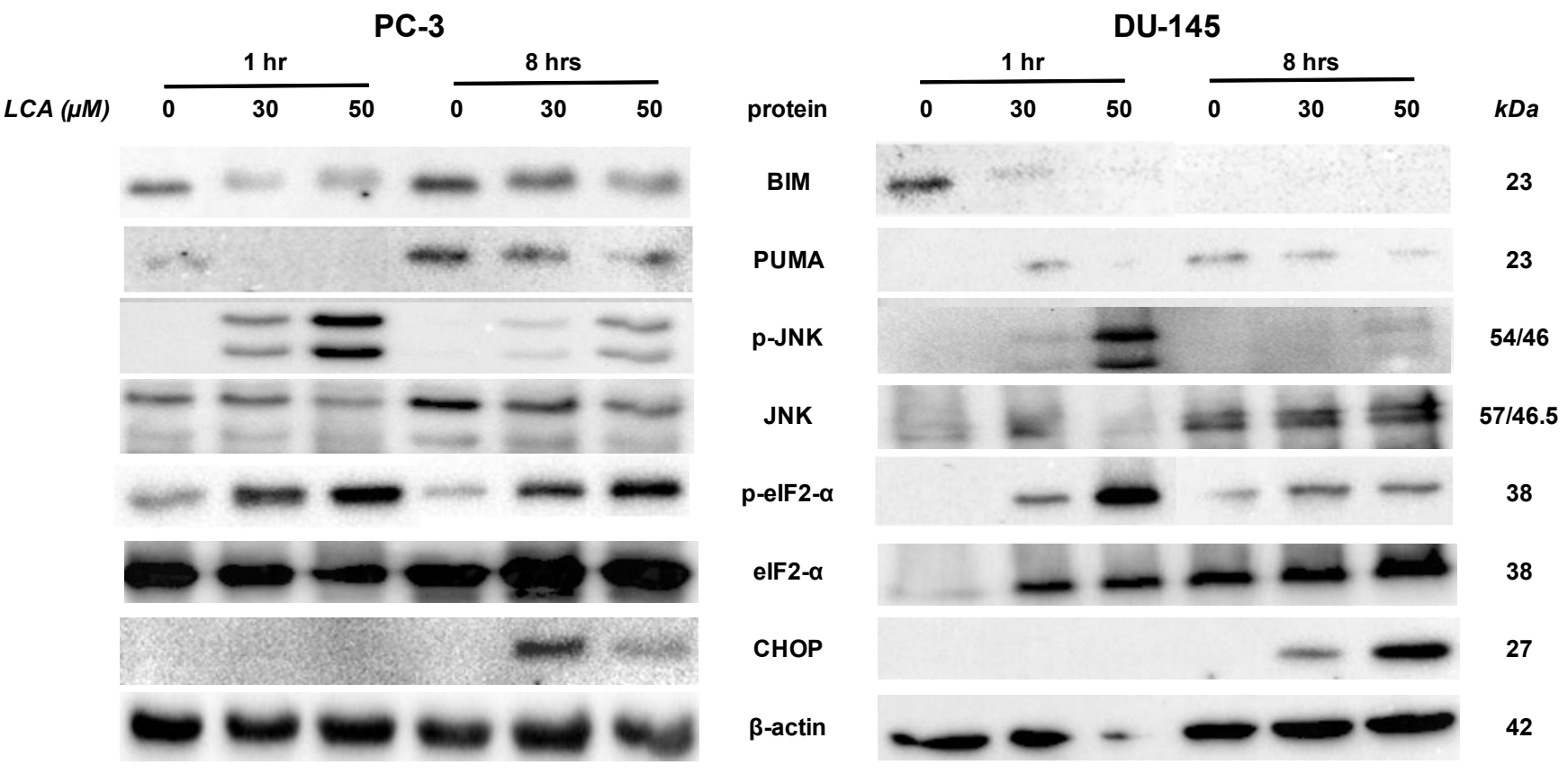


$27450 \mu M L C A$ for 1 and 8 h. BIM, PUMA, p-JNK, JNK, p-eIF $2 \alpha$, eIF $2 \alpha, C H O P$ and $\beta$-actin were

275 detected by immunoblotting; one representative gel of three is shown.

276

277 ER stress-inhibitor salubrinal and CHOP gene-silencing do not abrogate LCA-induced

278 cytotoxicity or apoptosis

279 To determine the role of ER stress in causing the cytotoxicity of LCA to PC-3 and DU-145 cells,

280 each cell type was pretreated for $4 \mathrm{~h}$ with salubrinal, a selective inhibitor of eIF2 $\alpha$

281 dephosphorylation, before exposure to toxic concentration of 30 or $50 \mu \mathrm{M}$ LCA. After an 8-h

282 exposure, LCA increased levels of cleaved caspase 3, p-eIF2 $\alpha$ and CHOP in both cell lines (Fig

283 5). Salubrinal pretreatment reduced each of these LCA-mediated increases in PC-3 cells,

284 although in DU-145 cells salubrinal pretreatment increased CHOP levels induced by $50 \mu \mathrm{M}$

285 LCA (Fig 5). In addition, salubrinal pretreatment did not alleviate LCA-induced death of PC-3

286 and DU-145 cells, but exacerbated the toxicity of LCA statistically significantly at most test

287 concentrations (Fig 6).

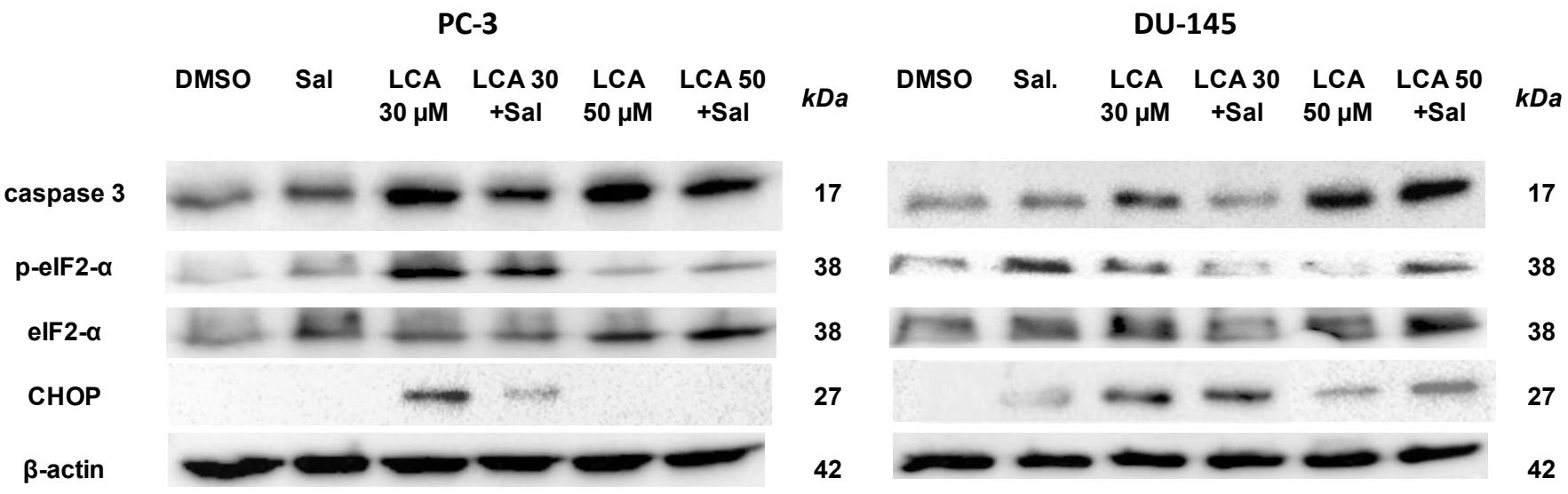

288

Figure 5. The effects of salubrinal-pretreatment on lithocholic acid-(LCA)-induced cleaved caspase 3, p-eIF $2 \alpha$ and CHOP levels in PC-3 and DU-145 prostate cancer cells. PC-3 and DU145 were exposed to LCA (30 and $50 \mu M)$ for $8 h$ in the presence or absence of $20 \mu M$ salubrinal. The expression of caspase-3, p-eIF $2 \alpha$ and CHOP was determined by immunoblotting; one representative gel of three is shown. 

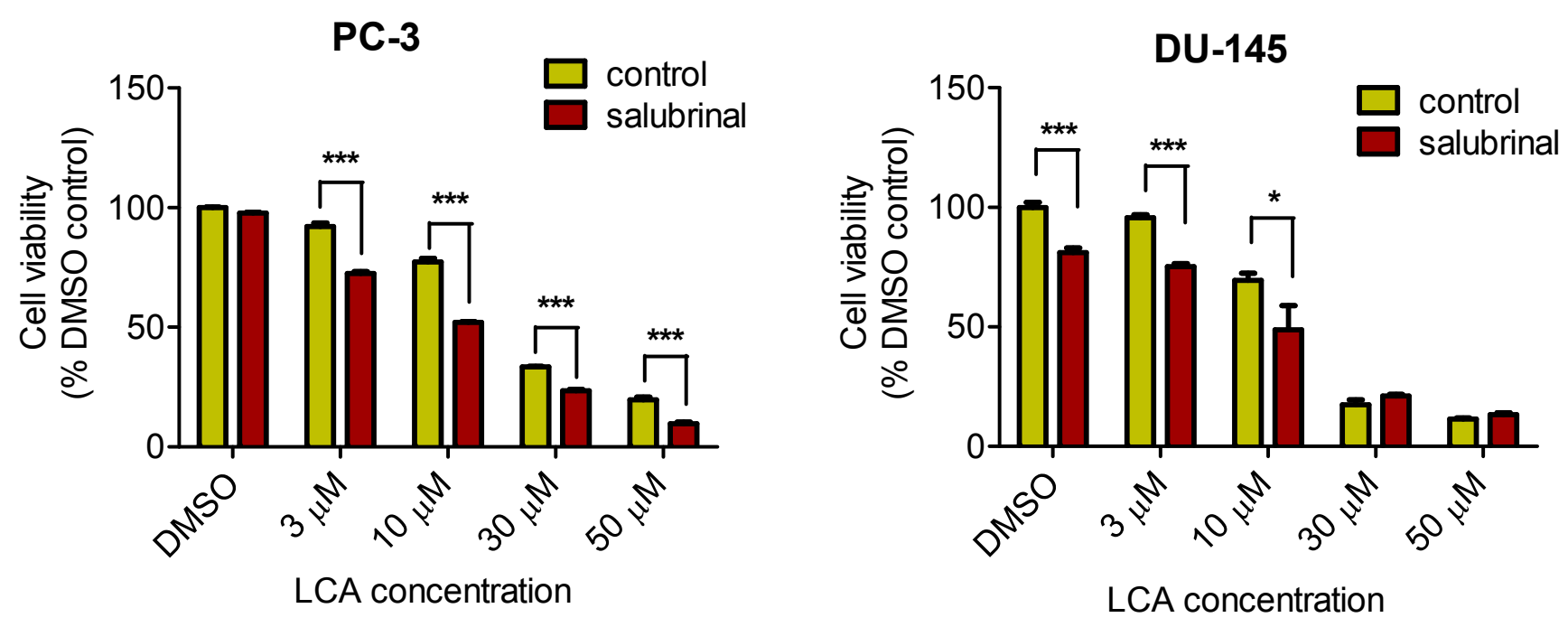

Figure 6. Salubrinal-pretreatment exacerbates the cytotoxicity of lithocholic acid (LCA) in PC-3 and DU-145 prostate cancer cells (24 h exposure). Statistically significant differences in cell viability between salubrinal-treated and vehicle control-treated cells were observed by twoway ANOVA and Bonferroni post-hoc test $(* p<0.05 ; * * * p<0.001)$. Experiments were performed in triplicate using different cell passages; per experiment each concentration was tested in triplicate.

301

302

Given that salubrinal-pretreatment further increased levels of LCA-induced CHOP in DU-145 cells, we assessed the effect of blocking CHOP gene expression using CHOP-selective siRNA. Gene silencing reduced LCA-induced levels of CHOP protein to undetectable levels in DU-145 cells (Fig 7A). However, no effect of CHOP silencing on LCA-induced cytotoxicity in DU-145 cells was observed (Fig 7B). This was confirmed using Hoechst staining to evaluate the effect of CHOP silencing on LCA-induced apoptosis in both DU-145 and PC-3 cells (Fig 8). 


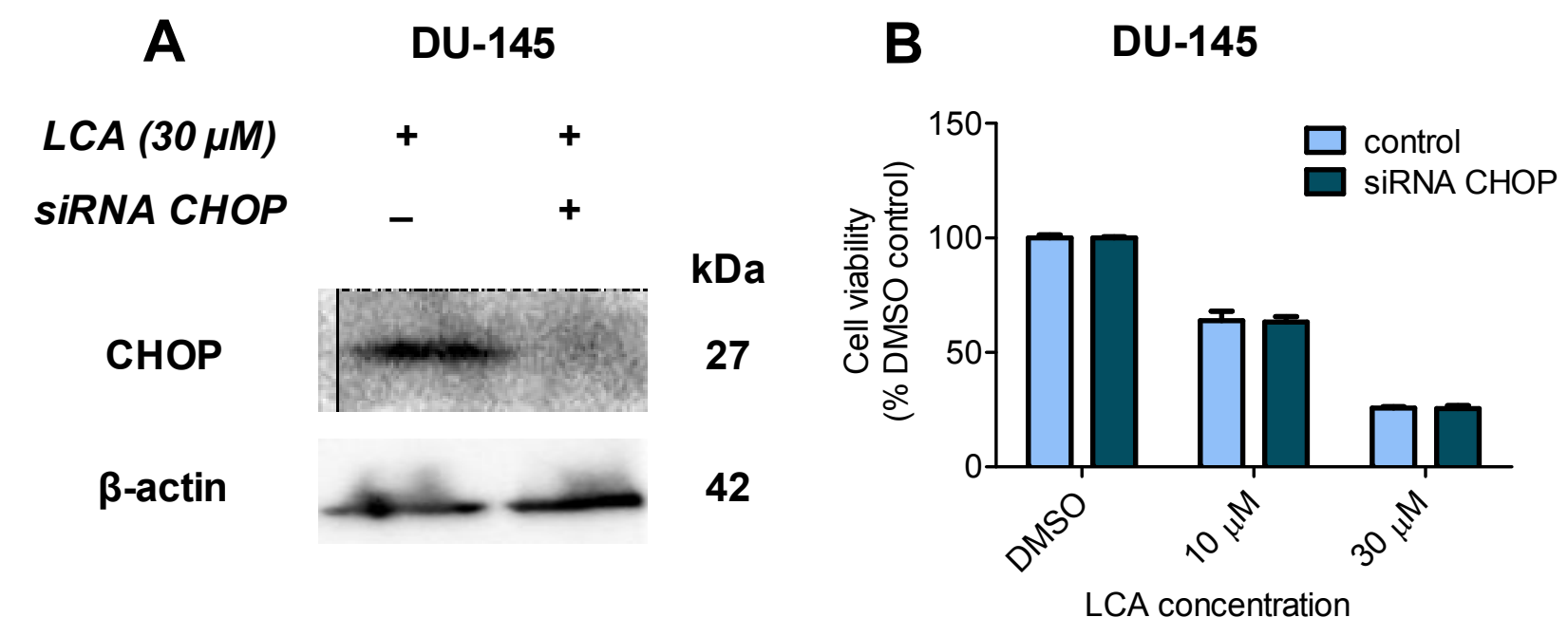

309

310 Figure 7. CHOP gene silencing does not affect lithocholic acid-(LCA)-induced cytotoxicity in

311 DU-145 prostate cancer cells. No statistically significant effects were observed of siRNA

312 treatment on control or LCA-decreased DU-145 cell viability by two-way ANOVA ( $p=0.9$;

$313 n=3)$.

314

315 
319 Figure 8. CHOP gene silencing does not affect lithocholic acid-(LCA)-induced apoptosis in PC-3 and DU-145 prostate cancer cells. Apoptotic nuclear morphology (chromatin condensed nuclei) was observed by Hoechst 33342 staining using fluorescence microscopy. The concentration-response experiment was performed three times using different cell passages; per experiment, concentrations were tested in triplicate. 


\section{LCA induces autophagy in PC-3 cells}

324 PC-3 cells exposed to increasing concentrations of LCA for $24 \mathrm{~h}$ were stained with Cyto ID

325 Green to detect the formation of autophagic vacuoles. A significant concentration-dependent

326 increase of green fluorescence signal was observed starting at an LCA concentration as low as 1

$327 \mu \mathrm{M})$ (Fig 9). Further confirming the autophagic response, a concentration-dependent increase of

328 the conversion of LC3B I to LC3B II was observed in PC-3 cells (Fig 10). A time-course

329 experiment indicated that noticeable conversion of LC3B was seen as early as $1 \mathrm{~h}$ after exposure

330 to 30 or $50 \mu \mathrm{M}$ LCA (Fig 10). When PC-3 cells were pretreated with the autophagy inhibitor

331 bafilomycin A1, the toxicity of relatively non-toxic concentrations of LCA (3 and $10 \mu \mathrm{M})$ was

332 increased to a statistically significant degree, whereas no effects on the toxicity of LCA were

333 observed at overtly toxic concentrations of 30 and $50 \mu \mathrm{M}$ (Fig 11A). Similarly, silencing LC3B

334 gene expression also increased the toxicity of LCA at lower concentrations (Fig 11B). To

335 establish if there was a link between induction of CHOP by LCA and that of autophagy, PC-3

336 cells were treated with siRNA to silence CHOP and then exposed to 30 or $50 \mu \mathrm{M}$ LCA (Fig 12).

337 CHOP silencing did not alter the increased conversion of LC3BI to II or alter the levels of ATG5

338 protein that were increased by LCA.

See high-definition Figure 9

Figure 9. Lithocholic acid (LCA) induces autophagy in PC-3 prostate cancer cells. Cells were

exposed to increasing concentrations of LCA for $24 \mathrm{~h}$ and then stained with Cyto-ID ${ }^{\circledR}$ Green dye

for 10 minutes to detect autophagic vacuoles. LCA concentration-dependently increased the

344 accumulation of autophagic vacuoles (bright green fluorescence) as detected by Cyto-ID®

345 Green dye staining using fluorescence microscopy. The concentration-response experiment was

346 performed three times using different cell passages; per experiment, concentrations were tested

347 in triplicate. 


\section{PC-3}

\begin{tabular}{|c|c|c|c|c|c|c|}
\hline \multirow[b]{2}{*}{$L C A(\mu M)$} & \multicolumn{5}{|c|}{$24 \mathrm{~h}$} & \multirow[b]{2}{*}{ kDa } \\
\hline & 0 & 3 & 10 & 30 & 50 & \\
\hline $\begin{array}{l}\text { LC3B I } \\
\text { LC3B II }\end{array}$ & 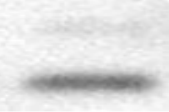 & - & $=$ & & $=$ & $16 \mid 14$ \\
\hline$\beta$-actin & & $=$ & $=$ & $=$ & $\longrightarrow$ & 42 \\
\hline
\end{tabular}

\begin{tabular}{|c|c|c|c|c|c|c|}
\hline \multirow[b]{2}{*}{$L C A(\mu M)$} & \multicolumn{3}{|c|}{$1 \mathrm{hr}$} & \multicolumn{3}{|c|}{8 hrs } \\
\hline & 0 & 30 & 50 & 0 & 30 & 50 \\
\hline LC3B I & & & & m. & & \\
\hline LC3B II & & 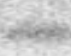 & nese & & mos & \\
\hline
\end{tabular}

$\beta$-actin

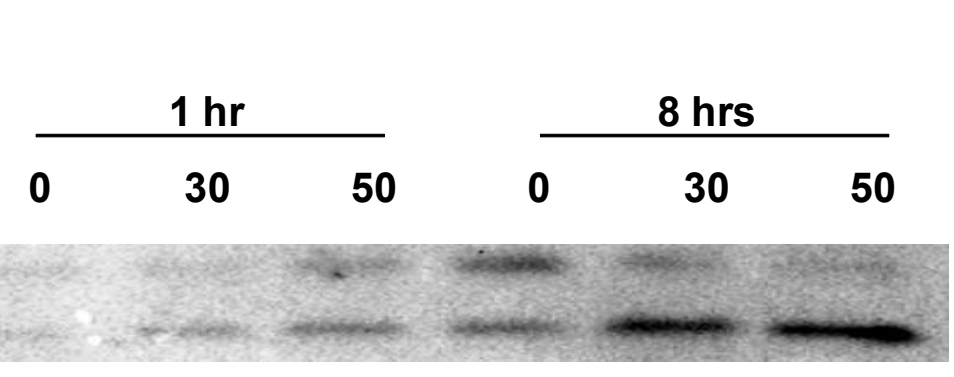

$\mathrm{kDa}$

16114

349 Figure 10. Lithocholic acid (LCA) induces LC3B conversion in PC-3 prostate cancer cells.

350 Cells were exposed to increasing concentrations of LCA for 1, 8 or 24 h. Proteins were detected 351 by immunoblotting; one representative gel of three is shown.
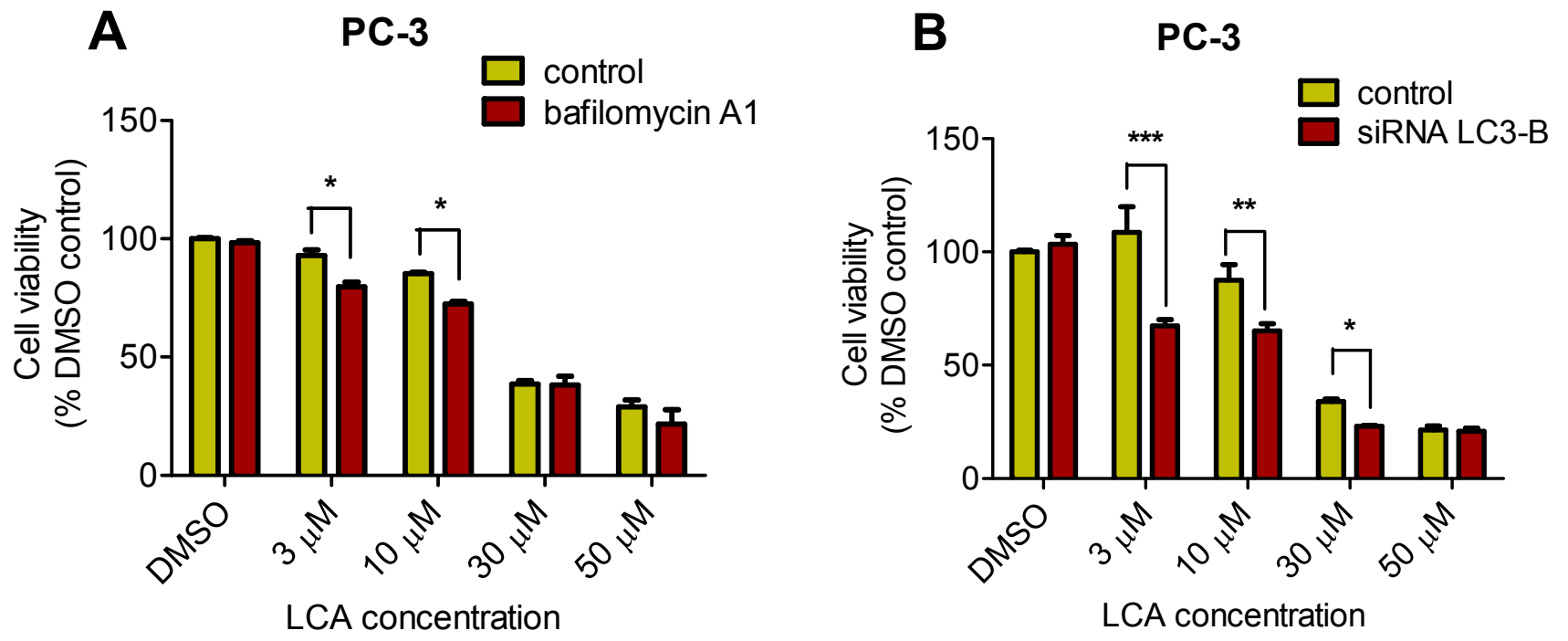

Figure 11. Bafilomycin A1-pretreatment (A) or LC3B gene silencing (B) enhanced the 
355 356 357 358 359 360

cytotoxicity of lithocholic acid (LCA) in PC-3 prostate cancer cells. Statistically significant differences in cell viability between bafilomycin A1- or LC3B siRNA-treated PC-3 cells and vehicle control-treated cells were determined by two-way ANOVA and Bonferroni post-hoc test $\left({ }^{*} p<0.05 ; * * p<0.01 ; * * * p<0.001\right)$. Experiments were performed in triplicate using different cell passages; per experiment, each concentration was tested in triplicate.

\section{PC-3}

\begin{tabular}{ccccccc} 
& & \multicolumn{3}{c}{$30 \mu \mathrm{M}$} & \multicolumn{3}{c}{$50 \mu \mathrm{M}$} \\
DMSO & MOCK & $30 \mu \mathrm{M}$ & LCA+ & $50 \mu \mathrm{M}$ & LCA+ & kDa \\
& & LCA & SiRNA & LCA & siRNA & \\
& & CHOP & & CHOP &
\end{tabular}

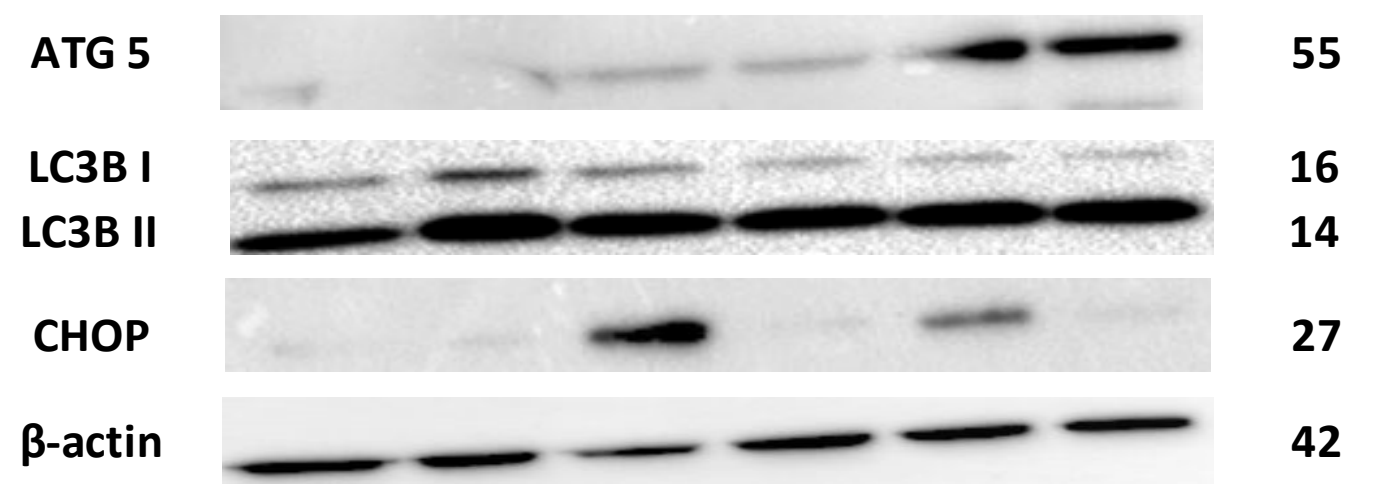

361

362

363

364

365

366

367

Figure 12. CHOP silencing had no affect on LCA-mediated induction of the autophagic markers LC3B conversion or ATG5 expression. Proteins were detected by immunoblotting; one representative gel of three is shown.

\section{LCA induces mitochondrial dysfunction in PC-3 and DU-145 cells}

Lithocholic acid induced mitochondrial dysfunction in PC-3 and DU-145 as measured using TMRE dye (Fig 13), which is sequestered by active mitochondria, but fails to accumulate in mitochondria that have reduced or lost their outer membrane potential. PC-3 and DU-145 were exposed to different concentration of LCA $(0,1,3,10$ and $30 \mu \mathrm{M})$ for $8 \mathrm{~h}$ and observed a concentration-dependent decrease in TMRE sequestration, which was most apparent at $30 \mu \mathrm{M}$ 
372 LCA (Fig 13). The loss of mitochondrial membrane potential coincided with an increase in

373 nuclear staining with Hoechst 33342 (Fig 13).

374

375

See high-definition Figure 13

376

377 Figure 13: Lithocholic acid induces mitochondrial dysfunction in PC-3 and DU-145 cells.

378 Cells were exposed to different concentrations of LCA for 8 hrs. Apoptotic nuclear morphology

379 (chromatin condensed nuclei) was observed by Hoechst 33342 staining and mitochondrial

380 membrane permeability was measured using TMRE fluorescent dye by fluorescence microscopy.

381 The concentration-response experiment was performed three times using different cell passages;

382 per experiment, each concentrations was tested in triplicate.

383

384 LCA induces reactive oxygen species (ROS)

385 LCA increased the production of ROS concentration dependently in PC-3 but not DU-145 cells 386 at concentrations between 1 and $50 \mu \mathrm{M}$. (Fig 14). To determine if the antioxidant $\alpha$-tocotrienol $387(\mathrm{~T}-3 ; 20 \mu \mathrm{M})$ could reduce the cytotoxicity of LCA, PC-3 and DU-145 cells were incubated with 388 T-3 four hours prior to a 24-h exposure to LCA. T-3 protected significantly against LCA-induced 389 cytotoxicity in PC-3 cells whereas in DU-145 cells, T-3 had no effect (Fig 15). 


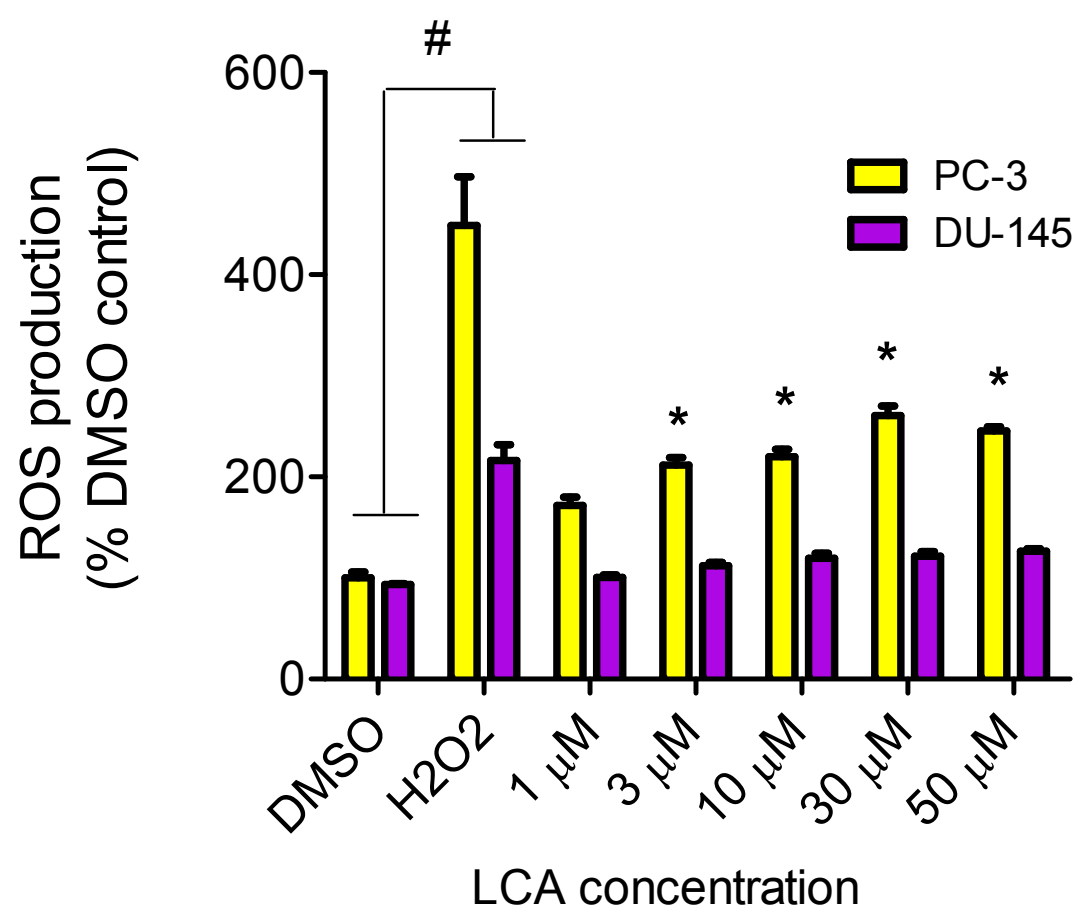

390

391

392

393

394

395

396

397

398

Figure 14. LCA induces reactive oxygen species (ROS) concentration dependently in PC-3 but not DU-145 cells. Cells were exposed to LCA for 60 minutes in culture medium containing 10 $m M$ fluorescent probe dye (CM-H2DCFDA). $\mathrm{H}_{2} \mathrm{O}_{2}(20 \mu M)$ was used as a positive control for ROS production, which was measured using a fluorescence spectrophotometer. \#) A statistically significant difference between DMSO- and $\mathrm{H}_{2} \mathrm{O}_{2}$-treated cells. *) A statistically significant difference between DMSO- and LCA-treated cells determined by one-way ANOVA followed by a Dunnett test. One of three experiments is shown; each concentration was tested in triplicate. 


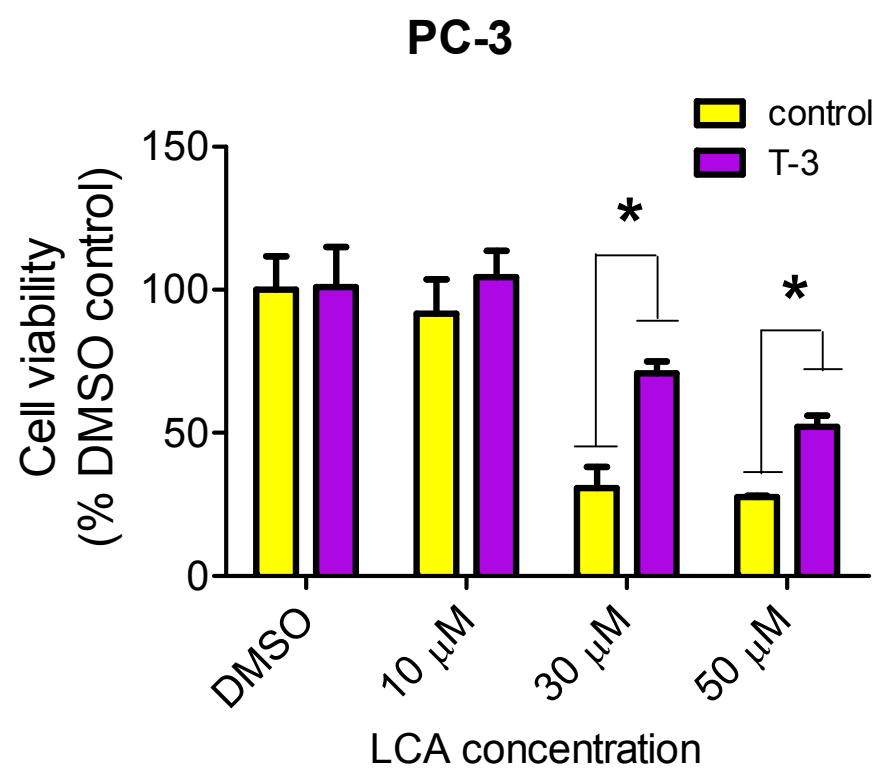

DU-145

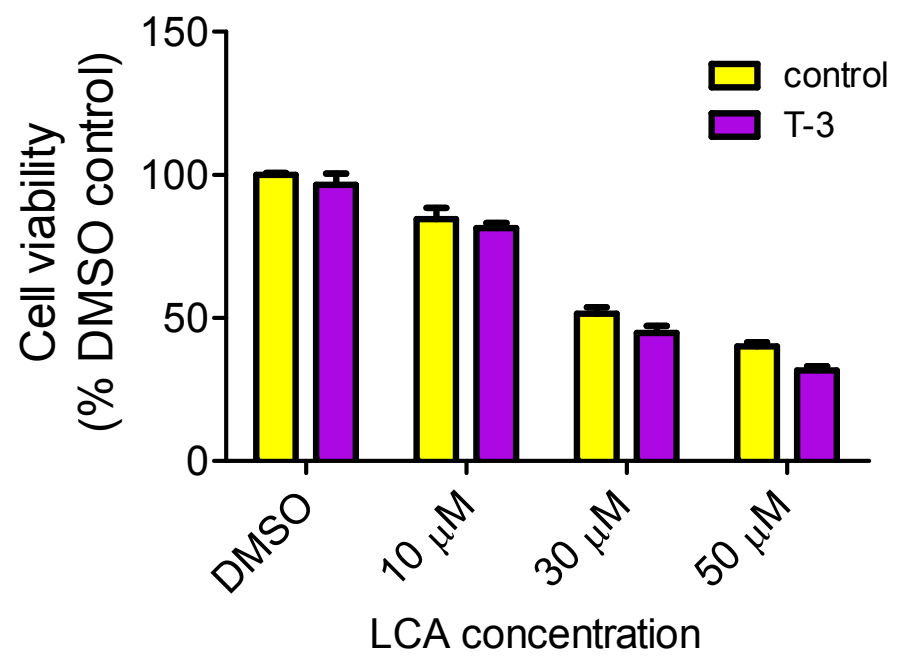

399

400 Figure 15. Effects of a 4-hour pretreatment with the antioxidant $\alpha$-tocotrienol $(\mathrm{T}-3 ; 20 \mu \mathrm{M})$ on the

401 cytotoxicity of LCA (24 h exposure) in (PC-3 cells or DU-145 cells. Statistically significant differences in 402 cell viability between antioxidant-treated and vehicle control-treated cells were observed by two-way 403 ANOVA and Bonferroni post-hoc test $(* p<0.05)$. One of three experiments is shown; each concentration 404 was tested in triplicate. 
406

407

408

409

410

411

412

413

414

415

416

417

418

419

420

421

422

423

424

425

426

427

428

429

430

431

432

433

434

\section{DISCUSSION}

\section{LCA induces selective cancer cell death}

In our study, we found that LCA reduces the viability of androgen-independent DU-145 and PC3 human prostate cancer cells, but not RWPE-1 immortalized human prostate epithelial cells (Fig 1), confirming and expanding upon our previous observations in prostate cancer cells that included androgen-dependent LNCaP cells (Goldberg et al., 2013). LCA triggered concentration-dependent death of PC3 and DU-145 cells via apoptotic and necrotic pathways (Fig 2). The selectiveness of LCA in killing cancer cells has recently been demonstrated in hepatocytes, where galactosylated poly(ethylene glycol)-conjugated LCA was toxic to HepG2 human hepatocarcinoma cells, but not to immortalized human LO2 liver cells (Gankhuyag et al., 2015). Furthermore, we have previously shown that LCA killed neuroblastoma cells, whilst sparing normal neuronal cells (Goldberg et al., 2011).

\section{LCA induces ER stress in prostate cancer cells}

We show for the first time that LCA induces ER stress in human androgen-independent prostate cancer cells in a time- and concentration-dependent manner (Fig. 3 and 4). Toxic concentrations of LCA reduced BIM and PUMA, and increased CHOP levels and the phosphorylation of eIF2 $\alpha$ and JNK in both cancer cell types. Increased phosphorylation of eIF $2 \alpha$ and JNK were early ( $1 \mathrm{~h}$ ) responses to toxic concentrations of LCA, whereas concentration-dependent decreases of BIM and PUMA were sustained between 1 and $24 \mathrm{~h}$ of exposure (Fig. 3 and 4). The increased cleavage of caspase 3 by LCA (Fig. 5) likely explains why BIM and PUMA levels decreased at toxic concentrations of LCA, as it is known that active caspase 3 downregulates PUMA (Hadji et al., 2010) and BIM (Wakeyama et al., 2007) expression in other cell types. At lower LCA concentrations and at earlier exposure durations, on the other hand, PUMA is initially increased, suggesting that PUMA is involved in triggering mitochondrial apoptosis (as discuss later) and caspase 3 activation that ultimately results in its breakdown. The up-regulation of PUMA is clearly p53-independent in PC-3 cells as these cells are p53-deficient (Rubin et al., 1991).

LCA caused sustained induction of CHOP at $30 \mu \mathrm{M}$ in PC-3 cells, although levels were sharply lower at $50 \mu \mathrm{M}$, possible due to excessive cell death (Fig 3-5). In DU-145 cells CHOP levels were increased by 30 and $50 \mu \mathrm{M}$ LCA, but levels declined between 8 and $24 \mathrm{~h}$ of exposure (Fig. 
4353 and 4). Our observations suggest that LCA-induced ER stress involves activation of the eIF2 $\alpha$ 436 phosphorylation pathway and subsequent induction of p-JNK (early response) and CHOP (later 437 response), resulting in caspase 3-dependent apoptosis. However, an attempt to block this 438 particular pathway with salubrinal reduced CHOP induction in PC-3 cells only, although it 439 decreased LCA-induced caspase 3 in both cell lines (Fig 5). Yet, salubrinal pretreatment resulted 440 in increased toxicity of LCA in both cell lines (Fig 6). We have previously shown that direct 441 inhibition of the catalytic activity of caspase 3 did result in partial protection against LCA442 induced cytotoxicity in LNCaP and PC-3 prostate cancer cells (Goldberg et al., 2013), and in 443 neuroblastoma cells (Goldberg et al., 2011). It is possible that the observed decreases in cleaved 444 caspase 3 protein levels do not reflect a significant change in its catalytic activity.

445 Furthermore, blocking CHOP expression using $C H O P$-selective siRNA had no effect on the 446 reduced viability (Fig 7) or apoptosis (as determined by measuring chromatin condensation and 447 fragmentation using the fluorescent dye Hoechst 33342) (Fig 8) of DU-145 and PC-3 cells after 448 exposure to increasing concentrations of LCA). Therefore, inhibition of ER stress signaling alone does not appear to be essential for LCA-induced prostate cancer cell death.

450

451

452

453

454

455

456

457

458

459

460

461

462

463

464

Other studies have observed the induction of ER stress by bile acids. In HepG2 cells, the secondary bile acids LCA and DCA were the most toxic, followed by CDCA, although they induced cell death at concentrations of $100 \mu \mathrm{M}$ and above (Adachi et al., 2014), which are significantly greater than the concentrations of LCA that we have found to be toxic to prostate cancer cells. The same investigators detected increased expression of genes involved in ER stress, such as GRP78 and CHOP after $24 \mathrm{~h}$ exposures to $100 \mu \mathrm{M}$ of LCA, DCA or CDCA. Using CDCA as a prototype bile acid, it was found to increase caspase 3 activity at $200 \mu \mathrm{M}$, but not $100 \mu \mathrm{M}$. Although cytotoxicity and CHOP induction, but not caspase 3 activation, appeared to occur concurrently after exposure to certain bile acids (Adachi et al., 2014), a direct link between ER stress and HepG2 cell death was not established. Glycochenodeoxycholic acid (GCDCA) has been shown to induce ER stress in freshly isolated rat hepatocytes and this study interestingly showed that ER stress-mediated activation of caspase 12 occurred at a later stage than mitochondrial apoptosis mediated by cytochrome c release and caspase 3 activation (Tsuchiya et al., 2006), suggesting induction of ER stress may not be critical to cell death. In a follow-up study, the investigators determined that caspase 8 activation via the extrinsic Fas 
465 pathway triggered ER stress in response to $300 \mu \mathrm{M}$ GCDCA in HepG2 human hepatocarcinoma 466 cells (Iizaka et al., 2007). It is unclear how critical caspase activation is for bile acid-induced cell 467 death. Glycodeoxycholate induced caspase 3-dependent apoptosis in rat hepatocytes after a $2 \mathrm{~h}$ 468 exposure and inhibition of caspase 3 activity resulted in less apoptosis, but whether this 469 translated into less cell death was not reported (Webster et al., 2002). We point out that these 470 previous studies were performed with remarkably high concentrations of bile acids and whether 471 cells were dying due to excess necrosis was never reported. We have previously shown in $472 \mathrm{LNCaP}$ and PC-3 prostate cancer cells that LCA (50 and $75 \mu \mathrm{M}$, respectively) activates caspases 4738,9 and 3, and that caspase 9 activation was likely secondary to caspase 8-induced truncation of 474 Bid (Goldberg et al., 2013), a finding consistent with those of (Iizaka et al., 2007). Inhibition of caspases 8 or 3 resulted in partial protection against LCA induced cytotoxicity, suggesting that the cytotoxicity of LCA is, at least in part, caspase-dependent (Goldberg et al., 2013). However,

477 we are currently performing studies to show that necrotic signaling pathways may play a 478 significant role in LCA-induced death of prostate cancer cells.

\section{LCA induces autophagy in PC-3 cells.}

480 We found that LCA induces a general autophagic response in PC-3 cells based on a time- and concentration-dependent increase of LC3B conversion observed in these cells (Fig. 9 and 10). To delineate the protective or cytotoxic nature of the autophagic response to LCA, cells were exposed to LCA after pre-incubation with the autophagy inhibitor bafilomycin A1. Cells were also treated with siRNA specific for LC3B to silence the expresssion of this protein. Inhibiting autophagy in PC-3 cells in either of these manners enhanced the toxicity of normally subcytotoxic concentrations of LCA (Fig 11A and 11B). This observation indicates that the autophagic response of PC-3 cells to LCA exposure is, at least initially, of a protective nature. Similarly, autophagy was shown to provide protection against cell death of rat hepatocytes induced by glycochenodeoxycholate, as its inhibition using the autophagy inhibitor chloroquine exacerbated toxicity whereas induction of autophagy using rapamycin provided protection against cell death (Gao et al., 2014). Our laboratory has also recently shown that blocking autophagy in $\mathrm{LNCaP}$ and $\mathrm{LNCaP} \mathrm{C} 4-2 \mathrm{~B}$ prostate cancer cells, resulted in a strong sensitization of these cells to the cytotoxicity of diindolylmethane and a series of ring-substituted 
494

495

496

497

498

499

500

501

502

503

504

505

506

507

508

509

510

511

512

513

514

515

516

517

518

519

520

521

522

dihalogenated DIM derivatives again demonstrating the protective nature of the autophagic process in these cells (Goldberg et al., 2015).

To our knowledge, this is the first reported observation that LCA induces autophagy in human (prostate) cancer cells, although a link between bile acids and autophagy has been recently proposed via activation of the farnesoid X receptor (FXR) (Nie et al., 2015). The FXR is a cytoplasmic receptor and an important target for hydrophilic primary bile acids, but is unlikely to play a large role in the biological effects of LCA, which is very hydrophobic and remains almost entirely outside the cell (Goldberg et al., 2013). More likely targets for LCA are cell membrane surface receptors such as the death receptors or the G-protein-coupled bile acid receptor (GPBAR1), the latter for which LCA has a particularly strong affinity. Although the role of the GPBAR1 in LCA mediated signaling in healthy cells is currently under intense investigation (Tiwari and Maiti, 2009; Stepanov et al., 2013; Fiorucci and Distrutti, 2015; Li and Chiang, 2015; Perino and Schoonjans, 2015), nothing is known about its functions in prostate cancer cells. Our preliminary results show strong expression of GPBAR1 protein in LNCaP, PC-3 and DU-145 cells and we are currently investigating the role of this receptor in triggering various cell death or survival pathways in these prostate cancer cells.

We did not establish a link between the induction of ER stress by LCA and its induction of autophagy. CHOP silencing did not alter the autophagic response of PC-3 cells to LCA at the tested concentration of 30 and $50 \mu \mathrm{M}$ as we observed no changes in the induction of LCB3 conversion or ATG5 protein levels (Fig 12). A recent study showed that whether triggering ER stress resulted in induction of either autophagy or apoptosis depended on the type of trigger. They found that triggering ER stress with thapsigargin only resulted in induction of apoptosis, whereas the ER stress inducer tunicamycin only caused autophagy (Matsumoto et al., 2013). However, it was not made clear whether the induction of either autophagy or apoptosis was directly mediated by ER stress or could have been due to off-target effects of the typical ER stress inducers. Our results indicate that the induction of ER stress by LCA was not directly responsible for the induction of either cell death or autophagy, and that likely these effects are secondary to the disruption of mitochondrial function by LCA.

\section{LCA induces mitochondrial dysfunction in PC-3 and DU-145 cells}


523 We have shown that LCA impairs mitochondrial function by increasing mitochondrial outer-

524 membrane permeability (Fig 13). These results confirm our earlier finding that LCA impairs

525 mitochondrial membrane potential in PC-3 and LNCaP cells as early as $1 \mathrm{~h}$ after exposure and

526 was sustained for at least $8 \mathrm{~h}$ (Goldberg et al., 2013). In the present study, we found that

527 induction of ROS by LCA (Fig 14) appeared to be a key trigger of cell death in PC-3 cells as the

528 antioxidant T-3 was able to protect these cells against the cytotoxicity of LCA (Fig 15).

529 Interestingly LCA did not induce ROS in DU-145 cells (Fig 14) and consistent with this,

530 antioxidant pretreatment had no protective effect against LCA-mediated cytotoxicity in these 531 cells (Fig 15). These remarkable differences in (anti)oxidative responses between the two cell 532 lines warrant further investigation.

\section{CONCLUSIONS}

535 In summary, we have found that LCA induces an ER stress response in PC-3 and DU-145 human 536 prostate cancer cells via a p-eIF2 $\alpha$-dependent pathway and an autophagic response in autophagy537 capable PC-3 cells. These pathways appear to play a cytoprotective role against LCA-induced

538 cell death, and are rather a response to the underlying, yet to be precisely elucidated mechanisms

539 of LCA-induced prostate cancer cell death. These underlying mechanisms appear to involve

540 induction of ROS and subsequent mitochondrial dysfunction in PC-3 cells, whereas in DU-145

541 cells LCA-induced mitochondrial dysfunction and cell death occurred at similar LCA

542 concentrations, yet in the absence of ROS formation.

543

\section{REFERENCES}

545 Adachi, T., Kaminaga, T., Yasuda, H., Kamiya, T., and Hara, H. (2014). The involvement of 546 endoplasmic reticulum stress in bile acid-induced hepatocellular injury. J Clin Biochem $547 \quad$ Nutr 54, 129-135.

548 Codogno, P., and Meijer, A. J. (2005). Autophagy and signaling: their role in cell survival and 549 cell death. Cell death and differentiation 12 Suppl 2, 1509-1518.

550 Conde, F. A., and Aronson, W. J. (2003). Risk factors for male osteoporosis. Urologic oncology 551 21, 380-383. 
552 Ferlay, J., Soerjomataram, I., Dikshit, R., Eser, S., Mathers, C., Rebelo, M., Parkin, D. M., 553 Forman, D., and Bray, F. (2015). Cancer incidence and mortality worldwide: sources, 554 methods and major patterns in GLOBOCAN 2012. Int J Cancer 136, E359-386.

555 Fimognari, C., Lenzi, M., Cantelli-Forti, G., and Hrelia, P. (2009). Apoptosis and modulation of 556 cell cycle control by bile acids in human leukemia T cells. Annals of the New York Academy of Sciences 1171, 264-269.

Fiorucci, S., and Distrutti, E. (2015). Bile Acid-Activated Receptors, Intestinal Microbiota, and the Treatment of Metabolic Disorders. Trends in molecular medicine 21, 702-714.

Gankhuyag, N., Singh, B., Maharjan, S., Choi, Y.-J., Cho, C.-S., and Cho, M.-H. (2015).

561

562

Galactosylated Poly(Ethyleneglycol)-Lithocholic Acid Selectively Kills Hepatoma Cells, While Sparing Normal Liver Cells. Macromolecular Bioscience 15, 777-787.

Gao, L., Lv, G., Guo, X., Jing, Y., Han, Z., Zhang, S., Sun, K., Li, R., Yang, Y., and Wei, L.

564

565 (2014). Activation of autophagy protects against cholestasis-induced hepatic injury. Cell \& bioscience 4, 47.

Giordano, C., Catalano, S., Panza, S., Vizza, D., Barone, I., Bonofiglio, D., Gelsomino, L., Rizza, P., Fuqua, S. A., and Ando, S. (2011). Farnesoid X receptor inhibits tamoxifenresistant MCF-7 breast cancer cell growth through downregulation of HER2 expression. Oncogene 30, 4129-4140.

Goldberg, A. A., Draz, H., Montes-Grajales, D., Olivero-Verbel, J., Safe, S. H., and Sanderson,

Goldberg, A. A., Beach, A., Davies, G. F., Harkness, T. A., Leblanc, A., and Titorenko, V. I. apoptosis selectively in androgen-dependent and -independent prostate cancer cells. PeerJ 1, e122. G., and Vazquez, A. (2010). Caspase-3 triggers a TPCK-sensitive protease pathway 
582

583

584

585

586

587

588

589

590

591

592

593

594

595

596

597

598

599

600

601

602

603

604

605

606

607

608

609

610

leading to degradation of the $\mathrm{BH} 3$-only protein puma. Apoptosis : an international journal on programmed cell death 15, 1529-1539.

Iizaka, T., Tsuji, M., Oyamada, H., Morio, Y., and Oguchi, K. (2007). Interaction between caspase- 8 activation and endoplasmic reticulum stress in glycochenodeoxycholic acidinduced apoptotic HepG2 cells. Toxicology 241, 146-156.

Katona, B. W., Anant, S., Covey, D. F., and Stenson, W. F. (2009). Characterization of enantiomeric bile acid-induced apoptosis in colon cancer cell lines. J Biol Chem $\mathbf{2 8 4}$, 3354-3364.

Levine, B., and Yuan, J. (2005). Autophagy in cell death: an innocent convict? The Journal of clinical investigation 115, 2679-2688.

Li, T., and Chiang, J. Y. (2015). Bile acids as metabolic regulators. Current opinion in gastroenterology 31, 159-165.

Malvezzi, M., Bertuccio, P., Rosso, T., Rota, M., Levi, F., La Vecchia, C., and Negri, E. (2015). European cancer mortality predictions for the year 2015: does lung cancer have the highest death rate in EU women? Annals of oncology : official journal of the European Society for Medical Oncology / ESMO 26, 779-786.

Marciniak, S. J., Yun, C. Y., Oyadomari, S., Novoa, I., Zhang, Y., Jungreis, R., Nagata, K., Harding, H. P., and Ron, D. (2004). CHOP induces death by promoting protein synthesis and oxidation in the stressed endoplasmic reticulum. Genes \& development 18, 30663077.

Martin, N. E., and D'Amico, A. V. (2014). Progress and controversies: Radiation therapy for prostate cancer. CA Cancer J Clin 64, 389-407.

Matsumoto, H., Miyazaki, S., Matsuyama, S., Takeda, M., Kawano, M., Nakagawa, H., Nishimura, K., and Matsuo, S. (2013). Selection of autophagy or apoptosis in cells exposed to ER-stress depends on ATF4 expression pattern with or without $\mathrm{CHOP}$ expression. Biol Open 2, 1084-1090.

Mizushima, N., Noda, T., Yoshimori, T., Tanaka, Y., Ishii, T., George, M. D., Klionsky, D. J., Ohsumi, M., and Ohsumi, Y. (1998a). A protein conjugation system essential for autophagy. Nature 395, 395-398. 
611 Mizushima, N., Sugita, H., Yoshimori, T., and Ohsumi, Y. (1998b). A new protein conjugation

612

613

614

615

616

617

618

619

620

621

622

623

624

625

626

627

628

629

630

631

632

633

634

635

636

637

638

639 system in human. The counterpart of the yeast Apg12p conjugation system essential for autophagy. J Biol Chem 273, 33889-33892.

Nguyen, P. L., Alibhai, S. M., Basaria, S., D'Amico, A. V., Kantoff, P. W., Keating, N. L., Penson, D. F., Rosario, D. J., Tombal, B., and Smith, M. R. (2015). Adverse effects of androgen deprivation therapy and strategies to mitigate them. Eur Urol 67, 825-836.

Nie, Y. F., Hu, J., and Yan, X. H. (2015). Cross-talk between bile acids and intestinal microbiota in host metabolism and health. J Zhejiang Univ Sci B 16, 436-446.

Perez, M. J., and Briz, O. (2009). Bile-acid-induced cell injury and protection. World journal of gastroenterology : WJG 15, 1677-1689.

Perino, A., and Schoonjans, K. (2015). TGR5 and Immunometabolism: Insights from Physiology and Pharmacology. Trends in pharmacological sciences 36, 847-857.

Reggiori, F., and Klionsky, D. J. (2002). Autophagy in the eukaryotic cell. Eukaryot Cell 1, 1121.

Rubin, S. J., Hallahan, D. E., Ashman, C. R., Brachman, D. G., Beckett, M. A., Virudachalam, S., Yandell, D. W., and Weichselbaum, R. R. (1991). Two prostate carcinoma cell lines demonstrate abnormalities in tumor suppressor genes. Journal of surgical oncology 46, 31-36.

Sanda, M. G., Dunn, R. L., Michalski, J., Sandler, H. M., Northouse, L., Hembroff, L., Lin, X., Greenfield, T. K., Litwin, M. S., Saigal, C. S., Mahadevan, A., Klein, E., Kibel, A., Pisters, L. L., Kuban, D., Kaplan, I., Wood, D., Ciezki, J., Shah, N., and Wei, J. T. (2008). Quality of life and satisfaction with outcome among prostate-cancer survivors. The New England journal of medicine 358, 1250-1261.

Shimodaira, Y., Takahashi, S., Kinouchi, Y., Endo, K., Shiga, H., Kakuta, Y., Kuroha, M., and Shimosegawa, T. (2014). Modulation of endoplasmic reticulum (ER) stress-induced autophagy by C/EBP homologous protein (CHOP) and inositol-requiring enzyme 1alpha (IRE1alpha) in human colon cancer cells. Biochem Biophys Res Commun 445, 524-533.

Society, A. C. (2015a). What are the key statistics about prostate cancer?

Society, C. C. (2015b). Prostate cancer statistics. 
640 Stepanov, V., Stankov, K., and Mikov, M. (2013). The bile acid membrane receptor TGR5: a 641 novel pharmacological target in metabolic, inflammatory and neoplastic disorders. 642 Journal of receptor and signal transduction research 33, 213-223.

643 Tiwari, A., and Maiti, P. (2009). TGR5: an emerging bile acid G-protein-coupled receptor target 644 for the potential treatment of metabolic disorders. Drug discovery today 14, 523-530.

645 Tsuchiya, S., Tsuji, M., Morio, Y., and Oguchi, K. (2006). Involvement of endoplasmic 646 reticulum in glycochenodeoxycholic acid-induced apoptosis in rat hepatocytes. Toxicol $647 \quad$ Lett 166, 140-149.

648 Wakeyama, H., Akiyama, T., Takahashi, K., Amano, H., Kadono, Y., Nakamura, M., Oshima, 649 Y., Itabe, H., Nakayama, K. I., Nakayama, K., Nakamura, K., and Tanaka, S. (2007). 650 Negative feedback loop in the Bim-caspase-3 axis regulating apoptosis and activity of 651 osteoclasts. J Bone Miner Res 22, 1631-1639.

652 Webster, C. R., Usechak, P., and Anwer, M. S. (2002). cAMP inhibits bile acid-induced 653 apoptosis by blocking caspase activation and cytochrome c release. American journal of 654 physiology. Gastrointestinal and liver physiology 283, G727-738.

655 